\title{
Formação de professores: saberes docentes para uma atuação intercultural
}

\author{
Teacher training: teaching knowledge for an intercultural performance \\ Formación docente: saberes docentes para el desempeño intercultural
}

Recebido: 01/02/2022 | Revisado: 05/02/2022 | Aceito: 13/02/2022 | Publicado: 19/02/2022

\author{
Lizandra Sodré Sousa \\ ORCID: https://orcid.org/0000-0001-7518-7461 \\ Universidade Federal do Maranhão, Brasil \\ E-mail: lizandra.sodre@ufma.br \\ Fausto Ricardo Silva Sousa \\ ORCID: https://orcid.org/0000-0002-4766-714X \\ Universidade Federal do Maranhão, Brasil \\ E-mail: fausto.ricardo@discente.ufma.br \\ Maria Zilma Rodrigues Silva \\ ORCID: https://orcid.org/0000-0001-8357-5923 \\ Universidade Federal do Maranhão, Brasil \\ E-mail: mzr.silva@discente.ufma.br \\ Suzana Rossi Pereira Chaves de Freitas \\ ORCID: https://orcid.org/0000-0002-5579-5387 \\ Universidade Federal do Maranhão, Brasil \\ E-mail: suzana.rossi@discente.ufma.br \\ Maria dos Reis Dias Rodrigues \\ ORCID: https://orcid.org/0000-0003-2502-0190 \\ Universidade Federal do Maranhão \\ E-mail: mrd.rodrigues@ discente.ufma.br \\ Sônia Maria de Jesus da Conceição \\ ORCID: https://orcid.org/0000-0002-1601-8315 \\ Universidade Federal do Maranhão, Brasil \\ E-mail: sonia.mjc@ discente.ufma.br \\ Jaciara da Silva Arruda \\ ORCID: https://orcid.org/0000-0001-9264-2534 \\ Universidade Federal do Maranhão, Brasil \\ E-mail: jaciara.arruda@ufma.br \\ Herli de Sousa Carvalho \\ ORCID: https://orcid.org/0000-0003-1503-4468 \\ Universidade Federal do Maranhão, Brasil \\ E-mail: herli.sousa@ufma.br
}

\section{Resumo}

A multiplicidade de grupos socioculturais que integram o espaço educativo é uma realidade presente nas escolas brasileiras. A despeito desta realidade, não se observa uma adequada abordagem no que diz respeito às práticas pedagógicas quanto às diferenças culturais no cotidiano escolar, especialmente em decorrência de não haver uma formação de professores que possa conduzir a um aprofundamento na temática. É nesse universo que se situa o presente trabalho. Nesse sentido, temos como objetivo analisar os saberes docentes necessários à formação de professores para uma atuação intercultural. A pesquisa se insere na abordagem qualitativa. Utilizamos a revisão bibliográfica a partir de estudos de autores que discutem a formação de professores, como Selma Garrido Pimenta (2012) e Miguel González Arroyo (2008, 2013, 2014a, 2014b), e aos que se dedicam a abordar a temática da interculturalidade nas práticas educativas, tais como: Vera Maria Candau (2008, 2012, 2014, 2016), Nilma Nilo Gomes (2007) e Reinaldo Matias Fleuri (2018a, 2018b). Concluímos, enfatizando que para avançar nessa perspectiva, há a necessidade da inserção do estudo da interculturalidade, dentre os saberes imprescindíveis nos processos de formação docente que possam subsidiar práticas pedagógicas democráticas.

Palavras-chave: Formação de professores; Interculturalidade; Saberes docentes; Ensino.

\begin{abstract}
The multiplicity of sociocultural groups that integrate the educational space is a reality present in Brazilian schools. Despite this reality, there is no adequate approach regarding pedagogical practices about cultural differences in school daily life, especially because there is no teacher training leading to a deeper understanding of this subject. It is in this universe that the present paper is situated. In this sense, we aim to analyze teaching knowledge necessary for teacher training to act interculturally. This research follows a qualitative approach. We use literature review based on studies from authors who discuss teacher training, such as Selma Garrido Pimenta (2012) and Miguel González Arroyo (2008,
\end{abstract}


2013, 2014a, 2014b), and those who address the issue of interculturality in educational practices, such as: Vera Maria Candau (2008, 2012, 2014, 2016), Nilma Nilo Gomes (2007) and Reinaldo Matias Fleuri (2018a, 2018b). We conclude by emphasizing that to advance in this perspective, it is necessary to include the study of interculturality, among the essential knowledge in the processes of teacher training to support democratic pedagogical practices.

Keywords: Teacher training; Interculturality; Teaching knowledge; Teaching.

\section{Resumen}

La multiplicidad de grupos socioculturales que integran el espacio educativo es una realidad presente en las escuelas brasileñas. A pesar de esta realidad, no existe un abordaje adecuado en cuanto a las prácticas pedagógicas respecto a las diferencias culturales en el cotidiano escolar, sobre todo como consecuencia de la falta de formación docente que pueda conducir a una comprensión más profunda del tema. Es en este universo que se sitúa el presente trabajo. En este sentido, nos proponemos analizar los saberes didácticos necesarios para la formación de docentes para un desempeño intercultural. La investigación se enmarca en un enfoque cualitativo. Utilizamos la revisión bibliográfica a partir de estudios de autores que abordan la formación docente, como Selma Garrido Pimenta (2012) y Miguel González Arroyo (2008, 2013, 2014a, 2014b), y de aquellos dedicados a abordar el tema de la interculturalidad en las prácticas educativas, como: Vera María Candau (2008, 2012, 2014, 2016), Nilma Nilo Gomes (2007) y Reinaldo Matias Fleuri (2018a, 2018b). Concluimos enfatizando que, para avanzar en esta perspectiva, es necesario incluir el estudio de la interculturalidad, entre los saberes esenciales en los procesos de formación docente que puedan sustentar prácticas pedagógicas democráticas.

Palabras clave: Formación docente; Interculturalidad; Enseñanza del conocimiento; Enseñanza.

\section{Introdução}

A multiplicidade de grupos socioculturais que integram o espaço educativo é uma realidade característica das escolas brasileiras. Entretanto, a educação escolar, tradicionalmente, vem compreendendo o universo de educandos de forma homogênea e uniforme, o que se evidencia com a implementação de currículos engessados que não respondem à pluralidade inerente ao contexto escolar. Nesse sentido, há uma discrepância entre a realidade plural e diversificada dos educandos e práticas pedagógicas que se desenvolvem de forma homogênea e padronizada.

Candau (2016) aponta que as relações étnico-raciais, as questões relativas ao gênero e sexualidade, a pluralidade religiosa, as culturas da infância e juventude, os povos tradicionais, dentre outros, são temáticas recorrentes na sociedade brasileira atualmente. Tais temas podem incitar controvérsias, intolerância ou preconceito, mas, ao mesmo tempo, conduz a iniciativas no sentido de possibilitar o direito às diferenças e o respeito aos cidadãos como um todo, a partir de práticas democráticas que desconstroem visões estigmatizantes acerca dos grupos socioculturais em suas especificidades.

Apesar de se observar inúmeros avanços quando se trata de políticas públicas que visam garantir os direitos dos grupos socioculturais tradicionalmente excluídos, a realidade do espaço escolar evidencia, por vezes, uma carência de práticas docentes efetivamente democráticas que possibilitem uma educação emancipadora. Nesse sentido, compreendemos a necessidade de que os processos de formação de professores possam garantir uma formação para a diversidade que se concretize em práticas educativas interculturais.

É nesse universo que se situa o presente trabalho, que possui como objetivo principal analisar os saberes docentes necessários à formação de professores para uma atuação intercultural. Partimos da compreensão da importância de que práticas pedagógicas interculturais sejam inseridas no cotidiano educativo. Com a pesquisa, buscamos responder ao seguinte questionamento: a formação de professores tem trazido saberes crítico-reflexivos que possam conduzir a uma prática pedagógica intercultural no contexto escolar?

Este estudo é composto por três seções. Na primeira, evidenciamos nosso percurso metodológico, destacando a abordagem que sustenta o estudo desenvolvido e o tipo de pesquisa que se tornou recurso para a construção das reflexões e análises contidas no decorrer do texto. Além disso, nessa seção evidenciamos ainda os autores e autoras que fundamentaram nosso embasamento teórico para todo o percurso do presente artigo. 
$\mathrm{Na}$ segunda seção, buscamos discutir os processos de formação de professores a partir do entendimento de que a formação deve proporcionar saberes alinhados às necessidades da sociedade atual. Nessa perspectiva, refletimos criticamente acerca do currículo morto, que se mostra pouco efetivo na função de formar educadores atentos às especificidades dos grupos socioculturais e às vicissitudes que se apresentam em dado momento social, cultural e histórico. Além disso, evidenciamos a importância do olhar comprometido e sensível para os educandos no desenvolvimento de práticas pedagógicas educativas, compreendendo que neles devem se situar o ponto central da atuação docente.

$\mathrm{Na}$ terceira seção, buscamos trazer alguns apontamentos que remontam à interculturalidade na prática educativa. Partimos do princípio de que a educação está imersa no processo cultural em que se situa, desta forma não há como desvincular a experiência pedagógica das questões culturais, conforme Candau (2008). Nesse sentido, compreendemos a relação indissociável entre educação e cultura, sendo assim, elas precisam de uma articulação, não somente a nível teórico, mas principalmente, no desenvolvimento prático-educativo.

Por fim, cumpre-nos ressaltar a importância de pesquisas que atuam nessa perspectiva, possibilitando reflexões acerca dos saberes necessários à docência e ressignificando os processos de formação de professores. Além disso, para além de teorizar sobre a formação docente, esta pesquisa contribui para direcionar uma atuação docente coadunada à realidade, tendo em vista o papel social do educador enquanto aquele que se compromete com uma educação digna, de qualidade e, acima de tudo, democrática.

\section{Metodologia}

Com a intenção de apresentar algumas reflexões válidas e aprofundadas acerca da relação entre formação docente e o desenvolvimento de uma educação que seja de fato intercultural, a pesquisa ancora-se em uma abordagem qualitativa por buscar compreender um fenômeno da realidade em sua complexidade e em seu contexto natural e histórico, coadunando-se aos propósitos do trabalho. Sendo assim, nossa pesquisa está abarcada pela compreensão de Elizabeth Teixeira (2005, p. 140), "na pesquisa qualitativa, o social é visto como um mundo de significados passível de investigação e a linguagem dos atores sociais e suas práticas as matérias-primas dessa abordagem. É o nível dos significados, motivos, aspirações, atitudes, crenças e valores, que se expressa pela linguagem comum e na vida cotidiana, o objeto da abordagem qualitativa".

Desenvolvemos uma revisão bibliográfica que, de acordo com Marconi e Lakatos (2003, p. 183), tem por finalidade "[...] colocar o pesquisador em contato direto com tudo o que foi escrito, dito ou filmado sobre determinado assunto, inclusive conferências seguidas de debates que tenham sido transcritos por alguma forma, quer publicadas, quer gravadas". Para tanto, fizemos uso das produções teóricas de Selma Garrido Pimenta (2012), Miguel González Arroyo (2008, 2013, 2014a, 2014b), Vera Maria Candau (2008, 2012, 2014, 2016), Nilma Nilo Gomes (2007), Reinaldo Matias Fleuri (2018a, 2018b), dentre outros, que possibilitam a contextualização, problematização, reflexão e análise sobre a formação de professores e as práticas educativas interculturais.

\section{Saberes Docentes e a Formação de Professores}

A educação se faz presente em toda sociedade, sendo constituinte da experiência humana e responsável pela construção de valores, conhecimentos e identidades. As aprendizagens são desenvolvidas desde a tenra infância, a partir da interação entre o ser humano e o meio social. Segundo Pimenta (2012), a educação se configura enquanto um processo de humanização que possibilita aos indivíduos darem prosseguimento ao processo civilizatório.

A educação escolar, mais especificamente, é responsável por processos educativos sistemáticos e intencionais e está assentada "no trabalho dos professores e dos alunos, cuja finalidade é contribuir com o processo de humanização de ambos pelo trabalho coletivo e interdisciplinar destes com o conhecimento, numa perspectiva de inserção social crítica e transformadora" 
(Pimenta, 2012, p. 25). É nesse contexto que se situa o trabalho docente enquanto um campo de atuação crucial para a formação humana, exercendo profunda influência na formação vivencial dos sujeitos.

Os estudos mostram que a formação curricular da maioria dos professores volta-se para uma volumosa transmissão de conteúdo, disciplinas e metodologias. Esta formação mostra-se insuficiente quando há a inserção deste profissional na prática educativa em que precisa dialogar com a complexidade da dinâmica sociocultural dos sujeitos. Na concepção de Arroyo (2008, p. 55) "aprendemos disciplinas sobre que conhecimentos da natureza e da sociedade ensinar e com que metodologias, porém não entra nos currículos de formação como ensinar-aprender a sermos humanos. Falta-nos a matriz pedagógica fundante".

Desse modo, muitos currículos escolares se apresentam superados e resistentes às características da dinâmica da realidade atual. Os professores possuem um importante papel na construção de currículos vivos, enriquecidos com conhecimentos que garantam aos educandos uma diversa produção de conhecimentos, a partir de uma leitura de mundo aprofundada e crítica. Desta forma, cumpre-nos compreender os processos de formação pelos quais este profissional caminha, na medida em que sua profissão é fundamental no que diz respeito à "mediação nos processos constitutivos da cidadania dos alunos, para o que concorre a superação do fracasso e das desigualdades escolares" (Pimenta, 2012, p. 15).

As demandas da sociedade contemporânea apontam a necessidade de que sejam pensadas novas possibilidades para a formação docente, a partir da reflexão e da reestruturação dos saberes que configuram a docência. A realidade aponta a presença de educandos que não mais se encaixam no imaginário docente da infância e juventude, conforme Arroyo (2014a). Segundo o mesmo autor, as infâncias, adolescências e juventudes são outras, que trazem para a realidade escolar suas vivências no campo, nas ruas e na cidade. Nesse sentido, compreendemos a necessidade de uma atuação que contemple os educandos em sua singularidade, visibilizando a diversidade inerente a esse grupo.

A profissão docente, portanto, possui um caráter dinâmico, que precisa estar alinhado às realidades sociais, situadas em dado contexto histórico. De acordo com Pimenta (2012):

Dada a natureza do trabalho docente, que é ensinar como contribuição ao processo de humanização dos alunos historicamente situados, espera-se da licenciatura que desenvolva nos alunos conhecimentos e habilidades, atitudes e valores que lhes possibilitem permanentemente irem construindo seus saberes-fazeres docentes a partir das necessidades e desafios que o ensino como prática social lhes coloca no cotidiano (Pimenta, 2012, pp. 18 e 19).

$\mathrm{Na}$ perspectiva da autora supracitada, os processos de formação docente devem conduzir os professores a uma compreensão ampliada da realidade em que se situa, além de desenvolver neles a capacidade de refletir acerca de suas práticas, vivenciando um processo de construção de identidade docente, viabilizado a partir da contínua transformação dos seus saberesfazeres docentes.

No entanto, Pimenta (2012) observa que os cursos de formação pouco têm favorecido a construção de uma nova identidade docente, à medida em que se ancoram em currículos distanciados do cotidiano escolar, que não contemplam as incoerências presentes na prática social de educar. Desta forma, pode-se observar uma fragilidade em responder adequadamente às demandas sociais que se apresentam nas escolas, o que coloca em evidência a importância de que seja repensada a formação docente e, consequentemente, o seu processo de formação identitária.

Arroyo (2014b), por sua vez, ressalta a importância de se conhecer melhor os educandos, compreendendo que a forma como estes são percebidos possui relação direta com a própria autoimagem do docente e de sua formação. Nesse sentido, o autor conduz a refletir que quando mudamos a forma de olhar os educandos, "nós mudamos como professores" (Arroyo, 2014b, p. 56), ressaltando que as imagens atribuídas a grupos pertencentes às classes populares, rotineiramente, são constituídas de forma negativa em comparação aos demais. 
Nos currículos de formação de professores, a ênfase em questões de ordem estritamente metodológica e conteudista contribui para a desvalorização do saber sobre os educandos. Arroyo (2014b, p. 60) afirma que "os sujeitos da ação educativa educadores-docentes e educandos-alunos vêm merecendo um olhar mais atento nos cursos de formação". Nessa perspectiva, os conhecimentos técnicos ensinados na maioria dos currículos formais não podem prescrever um saber orientado para o universo sociocultural dos educandos.

De acordo com Gomes (2007), inúmeros conhecimentos produzidos ao longo dos séculos não se fazem presentes nos currículos e na formação de professores, especialmente os conhecimentos produzidos pela comunidade negra em suas lutas de enfrentamento ao racismo, os conhecimentos produzidos pelas mulheres na busca pela igualdade de gênero, os conhecimentos produzidos pela juventude em suas vivências etc. A inserção desses conhecimentos é urgente e necessária para a possível superação de desigualdades socioculturais que se perpetuam nas escolas.

Os educandos devem ser o ponto central das práticas pedagógicas. Portanto, entendemos que os currículos precisam partir de uma compreensão ancorada na educação integral, que compreenda o sujeito em sua dimensão biopsicossocial, imerso em determinado contexto social, político e econômico.

Na percepção de Arroyo (2014b), para que os professores estejam sensíveis a novas didáticas, novo tempos de formação e socialização, também é importante uma sensibilidade humana quanto a olhar os educandos como sujeitos sociais, culturais, cognitivos e éticos. Desta maneira, pontuamos a sensibilidade no olhar para o educando como uma característica necessária para a formação do educador, produzindo influências significativas nos processos educativos nos quais estão inseridos.

A atuação docente precisa possibilitar o entendimento do estudante em sua pluralidade e, ao mesmo tempo, enquanto unidade de ser humano. Nas palavras de Arroyo:

Em cada aluno(a) há uma história pessoal, grupal, de gênero, raça, classe ou idade. Percursos singulares e coletivos que se entrelaçam com seus percursos escolares. É impossível pretender entender estes isolados daqueles. É impossível entender-nos como professores sem entender a totalidade dos percursos dos educandos. Por trás de cada nome que chamamos na lista de chamada se fará presente um nome próprio, uma identidade social, racial, sexual, de idade" (Arroyo, 2014b, p.64)

Sendo assim, a atuação dos professores deve voltar-se para a compreensão ampliada dos sujeitos que se encontram nas salas de aulas em seus percursos vivenciais.

Desta maneira, a construção de uma imagem profissional docente que supera estigmas, preconceitos e visões estereotipadas dos educandos perpassa por enxergá-lo em sua essência, apreendendo suas fragilidades, anseios e potencialidades. Para isso, faz-se crucial buscar o suporte teórico adequado nas ciências humanas, construindo um saber integral, social e, acima de tudo, humano.

Pimenta (2012) quando aborda os saberes necessários à docência discorre sobre a importância das experiências de cada professor para sua construção identitária, mas compreende que apenas a vivência em sala de aula não se mostra suficiente para uma formação consistente, sendo cruciais o conhecimento e os saberes pedagógicos: o conhecimento não se restringe a simples informação, mas se constrói do aprofundamento de informações, por meio de análises e contextualizações, já os saberes pedagógicos precisam partir das necessidades dadas pelo contexto real.

Para a autora "considerar a prática social como o ponto de partida e como ponto de chegada possibilitará uma ressignificação dos saberes na formação de professores" (Pimenta, 2012, p. 28). Nesta visão, observamos a necessidade de que seja tomado como referência as práticas já existentes, de modo a refletir sobre elas e nelas intervir. Os saberes pedagógicos, portanto, estruturam-se na ação, na práxis educativa, pois somente os saberes teóricos não se transformam em saberes pedagógicos. 
As práticas docentes, portanto, devem partir de uma atuação consonante à realidade em que está inserida. Arroyo (2013, p. 39) aponta que

É significativo que nas escolas e salas de aula onde chegam os(as) filhos(as) dos coletivos sociais, étnicos, raciais, das periferias e dos campos tenham lugar especial as inovações criativas dos docentes-educadores traduzidas em práticas e projetos; das formas indignas de viver que os educandos carregam venham indagações ao campo do conhecimento que obriguem seus profissionais a serem criativos para descartar conhecimento morto e incorporar indagações e conhecimento e significados vivos, instigantes para a docência.

A criatividade se apresenta como uma característica importante e necessária no trato docente com os educandos diversos, que precisa ser desenvolvida no cotidiano conforme a necessidade observada.

Nesta mesma compreeensão, Fleuri (2018a) defende que a escola deve possibilitar a aproximação com as realidades que os educandos vivenciam e, para isso, a formação de educadores se mostra como condição para que seja possível conduzir os estudantes a uma formação crítica e criativa, tanto a nível social quanto profissional. O autor parte da compreensão de que "a aprendizagem torna-se significativa para uma pessoa, na medida em que o processo educacional enseja a possibilidade de apreender novas informações, relacionando-as criticamente com os significados e as estruturas de significação que já vem desenvolvendo em sua vida pessoal e sociocultural" (Fleuri, 2018a, p. 137). Portanto, compreendemos a importância de que a escola esteja alinhada à realidade sociocultural dos estudantes de modo a conduzi-los a uma formação crítica e reflexiva.

Os docentes são levados a questionar uma atuação que se firma em currículos que os obrigam a transmitir conhecimentos e teorias de forma acrítica, relegando a um segundo plano os alunos tradicionalmente excluídos desse contexto. Um currículo em que apenas o necessário está previso é um currículo limitante, aprisionador, sem possiblidades criativas. Diversos coletivos docentes têm investido embates, posicionando-se de forma contrária aos currículos padronizadores em prol de currículos em que a liberdade, a ética e a pluralidade são os fios condutores.

É nesse cenário que muitos profissionais encontram possibilidades e incentivos para duvidar e ousar em práticas criativas que levam os educandos a compreenderem a si mesmos e aos determinantes de sua própria vivência (Arroyo, 2013). Assim sendo, por mais que os currículos formativos apresentem fragilidades que precisam ser problematizadas e repensadas, os docentes têm a possibilidade de avançar em sua atuação, à medida em que passam a compreender os alunos em suas especificidadades, fragilidades e potencialidades e a desenvolver práticas que os contemplem, a partir da concepção da educação como prática libertadora.

Arroyo (2013) faz uma análise pertinente quando aborda a atuação docente quanto a práticas engessadas afirmando que o ser docente-educador não está relacionado ao cumprimento rígido de "rituais preestabelecidos" pelos currículos, mas a se guiar pela sensibilidade para o real, para a vida conforme se apresenta na realidade e pelas possibilidades de transgredir em alguns momentos para sustentar ideais ético-políticos. Portanto, a resistência dos professores é no sentido de garantir os direitos dos educandos a uma educação libertadora, bem como aos seus direitos de exercer a profissão com ética e respeito a todos que ingressam nos espaços educativos, contribuindo para uma permanência de qualidade e para a formação de cidadãos comprometidos com outros cidadãos.

\section{A Interculturalidade na Prática Educativa}

A escola configura-se um espaço de compartilhamento de vivências por períodos significativos, sendo assim, possui uma função que ultrapassa a transmissão de conteúdos previamente definidos pelo sistema educacional. O contexto escolar deve preocupar-se com uma formação holística dos sujeitos que o integram, de forma a contribuir para uma formação que seja “consciente e crítica em sociedade, capacitando-os a interagirem através do diálogo e de práticas inclusivas, cientes de quem sou 
eu e de quem é o outro entre suas diferenças e igualdades que contribuem para a formação da sociedade como um todo" (Santos \& Queiroz, 2018).

Nesse sentido, a formação crítica dos educandos perpassa por um processo de ensino e aprendizagem que seja por eles considerado significativo. Portanto, o despertar do interesse dos discentes pela aprendizagem decorre da reformulação de currículos que possibilitem a ressignificação dos indivíduos, a partir da inserção de questões sociais e culturais em seus eixos norteadores (Santos \& Queiroz, 2018). A pertença sociocultural permeia a vida dos sujeitos desde o seu nascimento, realidade que não pode ser desconsiderada quando se ingressa no espaço escolar.

Lima (2006) aponta que a diversidade é algo inerente à própria espécie humana, somos sujeitos singulares em experiências e visões de mundo. Dessa forma, não há educação que não esteja imersa nos processos culturais do contexto em que se situa. Conforme pontua Candau (2012) há uma urgência, no sentido de se trabalhar as questões de reconhecimento e valorização das diferenças culturais nos contextos educativos, para garantir o direito de todas as pessoas à educação. Neste sentido, não é possível conceber uma experiência pedagógica "desculturalizada", isto é, desvinculada totalmente das questões culturais da sociedade (Candau, 2008, p. 13). Sendo assim, a herança cultural de cada sujeito, dentro da escola, tende a ser potencializada ou fragilizada, conforme a atuação pedagógica que rege a aprendizagem, podendo ser produtora de uma educação emancipadora ou de uma educação que molde os educandos aos padrões estabelecidos pela sociedade.

Esse contexto aponta que as relações entre a cultura e a educação estão fixados em dois eixos principais, conforme definem Santos e Queiroz (2018), quais sejam: 1- um ensino etnocêntrico, que parte da monoculturalidade como premissa básica e perpetua os ideais das classes hegemônicas sociais, majoritariamente presente nos currículos escolares atuais; ou 2- um ensino intercultural, que não somente reconhece os indivíduos como seres únicos e heterogêneos, mas, principalmente, busca desenvolver diálogos e interrelações entre os diversos grupos socioculturais.

No que concerne ao primeiro eixo, observamos uma dificuldade dos educadores em conferir uma atuação que aponte a relevância da multiculturalidade presente no meio escolar. As práticas docentes, por vezes, são desenvolvidas de forma naturalizada de modo a não desenvolver questionamentos que identifiquem a que, a quem ou a quais sistemas se está servindo. O formato padronizado de se pensar a escola e sua dinâmica de organização tende a manter o sistema social estruturante, que se fundamenta nas desigualdades e nas vantagens de determinados grupos sobre aqueles considerados inferiores.

Essa realidade presente no cotidiano escolar conduz a um excessivo distanciamento entre as experiências socioculturais do aluno e da escola, favorecendo "uma baixa autoestima, elevados índices de fracasso escolar e a multiplicação de manifestações de desconforto, mal-estar e agressividade em relação à escola" (Candau, 2008, p. 27). Nesta perspectiva, os educandos que historicamente foram excluídos de uma educação libertadora acabam por vivenciar outros processos de exclusão mais sofisticados, o que os levam, muitas vezes, à evasão escolar.

Na concepção de Moreira (2012), o modelo de atuação que se sustenta na assimilação passiva dos educandos fortalece a ausência de diálogos entre os sujeitos no espaço educativo, contribuindo, portanto, para a estigmatização de determinadas culturas em detrimento de outras. De acordo com o mesmo autor, ao docente

[...] cabe procurar desafiar o viés monocultural do currículo; desestabilizar a hegemonia da cultura ocidental no currículo; socializar para todos os estudantes o conhecimento escolar, destacando seu caráter relacional e histórico; questionar as representações, as imagens e os interesses expressos em diferentes artefatos culturais, buscando explicitar as relações de poder neles expressas (Moreira, 2012, p. 189).

Portanto, as práticas monoculturais se perpetuam à medida em que, nas escolas, não se conduzem discussões acerca de outras versões das histórias, que não estejam fundamentadas unicamente nos ideais euro-americanos. 
Há, portanto, a demanda por um currículo que seja operacionalizado em práticas pedagógicas que perceba os sujeitos a partir de seu pertencimento étnico-racial, cultural, de gênero, geracional, enfim. O que nos conduz ao segundo eixo, que traz a compreensão de que "a cultura não deve ser vista como um tema e nem como disciplina, mas como um eixo que orienta as experiências e práticas curriculares" (Gomes, 2007, p. 28).

Parte-se da premissa de que os sujeitos são únicos e diversos. De acordo com Gomes (2007, p. 17)

[...] do ponto de vista cultural, a diversidade pode ser entendida como a construção histórica, cultural e social das diferenças. A construção das diferenças ultrapassa as características biológicas, observáveis a olho nu. As diferenças são também construídas pelos sujeitos sociais ao longo do processo histórico e cultural, nos processos de adaptação do homem e da mulher ao meio social e no contexto das relações de poder.

Sendo assim, as diferenças podem ser compreendidas como uma construção que se dá em determinado contexto cultural, não se restringindo à dimensão biológica do ser humano, mas, compreendendo a forma como os sujeitos se relacionam consigo e com o outro no mundo.

A implementação de práticas que reconhecem a diversidade cultural nas escolas é um desafio necessário, tendo em vista sua contribuição na formação de educandos críticos que se transformam em agentes de mudanças nos contextos sociais em que estão inseridos. Nesta perspectiva se assenta a interculturalidade enquanto a possibilidade de pensar a sociedade de forma mais plural, onde há o diálogo entre os diversos grupos independente de seus aspectos étnico-raciais, econômicos ou culturais.

A educação intercultural crítica, portanto, é um caminho possível para uma sociedade essencialmente democrática. Corroboramos com a conceituação proposta por Candau (2014, p. 1) quando afirma que:

A Educação Intercultural parte da afirmação da diferença como riqueza. Promove processos sistemáticos de diálogo entre diversos sujeitos - individuais e coletivos -, saberes e práticas na perspectiva da afirmação da justiça - social, econômica, cognitiva e cultural -, assim como da construção de relações igualitárias entre grupos socioculturais e da democratização da sociedade, através de políticas que articulam direitos da igualdade e da diferença.

Ainda de acordo com a autora supracitada, quando se trata do diferente, normalmente recorremos a visões inferiorizantes quando nos referimos àqueles que possuem rendimentos acadêmicos insuficientes, advindos de comunidades de risco ou que possuem alguma vulnerabilidade social. Ou seja, a percepção que preenche o imaginário de grande parte dos educadores quanto aos considerados diferentes é a de que são um problema a ser resolvido.

Entretanto, a pluralidade cultural não precisa ser entendida como algo a ser superado, pois a riqueza que lhe é inerente pode conduzir a práticas inovadoras e diferenciadas. Nesse sentido, os educadores têm a árdua tarefa de descontruir aspectos do cotidiano escolar que já se encontram naturalizados e que impedem o adequado reconhecimento das diferenças culturais, bem como suas potencialidades de atuação neste processo.

É necessário pontuarmos o fato de que a criticidade não se faz presente em toda educação que se diz intercultural. Walsh (2009) afirma que há dois tipos de interculturalidades, uma "funcional" e a outra "crítica". Na interculturalidade funcional, observamos um alinhamento no que diz respeito à classe dominante, enquanto na interculturalidade crítica, há possibilidades reais de diálogo democrático entre as culturas. De forma mais específica, quando se trata da realidade escolar, a interculturalidade de caráter funcional não considera as contribuições das culturas no processo educativo, sendo utilizadas abordagens simplistas e, muitas vezes, folclorizadas.

A interculturalidade crítica, por sua vez, ultrapassa essa visão reducionista para aprofundar-se em questões sociais, buscando compreender o cerne destas e desenvolvendo problematizações sobre as relações de poder estabelecidas socialmente e sobre como a educação legitima essa forma de pensar em prol do interesse de uma minoria (Santos \& Queiroz, 2018). Para Walsh (2009, p. 25) a interculturalidade crítica é uma ferramenta pedagógica que 
[...] questiona continuamente a racialização, subalternização, inferiorização e seus padrões de poder, visibiliza maneiras diferentes de ser, viver e saber e busca o desenvolvimento e criação de compreensões e condições que não só articulam e fazem dialogar as diferenças num marco de legitimidade, dignidade, igualdade, equidade e respeito, mas que - ao mesmo tempo - alentam a criação de modos "outros" - de pensar, ser, estar, aprender, ensinar, sonhar e viver que cruzam fronteiras.

Observamos, portanto, nesse pensamento, a possibilidade de resgatar discussões acerca das diversas identidades, desconstruindo perspectivas limitantes sobre o outro.

O espaço escolar se mostra propício para ações interventivas que fomentem o diálogo entre as culturas. Sendo assim, é crucial lidar com a pluralidade presente nesse espaço, reconhecendo os diferentes sujeitos inseridos em seu contexto (Moreira \& Candau, 2003). Isso implicaria em descontruir a tendência a uma visão etnocêntrica acerca do outo, promovendo espaços de reflexão, onde se possa exercitar o colocar-se no lugar sociocultural do outro, possibilitando a interrelação de culturas no contexto escolar.

A própria visão dos educadores acerca das questões advindas da diversidade cultural deve ser descontruída e problematizada, com vistas a uma mudança de postura docente e, consequentemente, de práticas educativas. Este é um passo fundamental para favorecer a superação do "daltonismo cultural" e promover uma educação intercultural (Candau, 2016), superando assim, a monoculturalidade enraizada nesse contexto. Sem essa mudança de percepção, a interculturalidade tende a se reduzir a atuações fragilizadas e esporádicas em determinados períodos do ano.

É salutar, portanto, que a perspectiva da educação intercultural crítica encontre espaço na formação inicial docente no Brasil. Na pesquisa desenvolvida por Pereira \& Pereira (2020, p. 17), os autores concluem que

A organização curricular da formação docente não tem espaço para práticas de educação intercultural, e tem consolidado uma formação eurocêntrica, monocolonial e descontextualizadas com os problemas emergentes da sociedade refletidos no campo educacional, e revelando o despreparo docente em nível de conhecimento teórico acerca da educação intercultural crítica no cotidiano escolar.

Esta realidade evidencia o descompasso existente entre as necessidades educativas atuais e as práticas institucionais e pedagógicas desenvolvidas, que ainda estão sob forte influência da perspectiva eurocêntrica.

Na visão de Canen (2001) é urgente e necessário que a conscientização cultural seja abordada na formação docente, considerando as representações e saberes docentes desenvolvidos nas vivências escolares, pois o foco ainda está muito voltado para aquilo que "falta", o que evidencia uma visão fragmentada dos estudantes. Nessa perspectiva, compreender a percepção e as representações docentes no cotidiano de suas práticas permite uma maior mobilização destes para a questão da pluralidade cultural, uma vez que todos os grupos étnico-raciais são reconhecidos como portadores de cultura. Desta maneira, será possível romper com a homogeneização cultural e combater as percepções negativas acerca daqueles que não se encaixam no padrão dominante.

A autora ainda pontua que a perspectiva intercultural crítica implica em reconhecer que a sensibilização intercultural não pode ser concebida de forma "dissociada da realidade do cotidiano docente, de suas representações e de seu saber, sob pena de se proceder à elaboração de programas e documentos curriculares que não se consubstanciem em práticas pedagógicas transformadoras" (Canen, 2001, p. 212). Nesse sentido, a formação docente na perspectiva intercultural crítica se faz necessária para uma atuação coadunada com a pluralidade inerente ao contexto escolar. Para isso, a interlocução teoria-prática se mostra fundamental para uma melhor compreensão da realidade a ser trabalhada.

Algumas ações mostram-se fundamentais nesse processo, tais como: conhecer o mundo cultural dos educandos e suas histórias de vida, observar elementos escolares que possam fomentar práticas estigmatizantes, desenvolver processos de escuta dos diversos atores educativos, refletir e problematizar como se estabelecem as relações na escola com relação ao tema, analisar 
criticamente documentos institucionais, viabilizar parcerias com instituições ou grupos que discutem a temática, possibilitar espaços de debates, dentre outros.

A perspectiva intercultural parte da ideia de um processo educativo dinâmico, em que a unidade da coletividade não anula as singularidades de cada pessoa, assim como a individualidade não seja fator de ruptura da coesão coletiva, conforme Fleuri (2018a, 2018b). Respeitar as peculiaridades e necessidades de cada um, assim como o ritmo de aprendizagem e a autonomia intelectual de cada educando é fundamental. Desta maneira serão desenvolvidas mediações complexas e interculturais que garantam a equidade de direitos e oportunidades, além de possibilitar o protagonismo dos estudantes e a relação dialógica entre educandos-educadores.

Este é um desafio para os professores e professoras que se veem inseguros/as frente a uma realidade para a qual, muitas vezes não foram preparados/as. Por isso a necessidade da autoformação e de uma formação continuada na área para minimizar o medo que advém com a presença do "novo". Uma prática docente complexa e intercultural pressupõe sair da zona de conforto e assumir novos modos de fazer que contemplem a diversidade inerente à sala de aula.

Ressaltamos o papel do educador enquanto aquele que atua na mediação da relação educativa, potencializando a capacidade de iniciativa e de interação dos estudantes. Mas para isso, o educador precisa ser produtor do seu próprio saber, elaborando o sentido a partir da articulação com a sua história de vida individual, com suas relações com a sociedade, com a instituição escolar, com os outros atores e lugares de formação, de acordo com Fleuri (2018b). Portanto, repensar e ressignificar a concepção de educador aponta para uma atuação que contribua para a potencialização das diferenças e interações críticas entre os sujeitos singulares no contexto educativo.

Finalmente, o percurso desenvolvido neste trabalho nos possibilita afirmar que a preparação dos alunos para uma forma crítica de perceber e viver as questões socioculturais passa pela reformulação dos processos de formação de professores, uma vez que "o professor é a peça-chave dessa reformulação", conforme pontuam Oliveira et al. (2022, p. 8). A atuação docente em uma perspectiva emancipatória é fundamental para conduzir ações interculturais que desenvolvam aproximações entre a realidade dos educandos e os aprendizados obtidos em sala de aula. Desta maneira, com uma atuação docente firmada no diálogo e na cooperação entre os mais diversos grupos, será possível construir uma sociedade um pouco mais justa, digna e igualitária.

\section{Considerações Finais}

No decorrer da pesquisa, buscamos desenvolver reflexões que conduzem à necessidade de reformulação dos currículos que integram os processos formativos docentes. De modo geral, os currículos atuais mostram-se enrijecidos e não proporcionam saberes suficientes para responder à complexidade inerente ao contexto educativo, especialmente no que tange à problemática da interculturalidade. Apesar da questão de a diversidade surgir como possibilidade de discussão na programação curricular dos cursos de licenciatura, não se constituem enquanto eixos norteadores.

$\mathrm{Na}$ formação de professores, os autores apontam lacunas no que tange ao conhecimento sistematizado dos educandos em suas especificidades. Em contraposição a essa realidade, compreendemos a necessidade de que o educador possua conhecimentos sobre os educandos em seu contexto sociocultural para o adequado desenvolvimento de práticas educativas que acolham as diferenças. A ausência desses saberes interfere negativamente nas práticas docentes e no olhar para os educandos, que deixam de ser vistos como seres únicos e plurais e passam a ser percebidos de maneira padronizada e simplista.

Portanto, o desenvolvimento de pesquisas com essa perspectiva contribui significativamente para o repensar dos currículos que orientam os cursos de formação de professores, bem como ressignificar os saberes necessários para o desenvolvimento de práticas pedagógicas democráticas. Há que se reinventar a educação escolar, de modo a oferecer espaços de aprendizagem que sejam condizentes aos contextos culturais, políticos e sociais da atualidade. 
Ressaltamos a importância de que outros estudos possam ser desenvolvidos para o aprofundamento da temática, apontando especificidades e possibilidades de uma atuação intercultural, considerando a realidade dos mais diversos contextos educativos, seja na educação básica, seja na educação superior ou profissionalizante. Apontar as especificidades de cada contexto de educação contribui para o desenvolvimento significativo de saberes e a efetiva inserção de práticas interculturais no cotidiano escolar.

Podemos afirmar que já é possível observar a existência de experiências educativas que se sustentam em uma perspectiva de atuação plural, avançando para novos paradigmas, a partir da reestruturação de currículos, da reformulação de práticas pedagógicas, do desenvolvimento de vínculos com famílias e comunidades, da participação popular nas tomadas de decisão, enfim, da ênfase na pluralidade escolar. Entretanto, tais experiências não constituem majoritariamente o contexto educativo, permanecendo pontuais e isoladas da realidade como um todo, tendo em vista que não são devidamente visibilizadas ou apoiadas.

Por fim, concluímos que a educação é um direito de todos e sendo de todos precisa necessariamente ser desenvolvida para todos, considerando as singularidades e as diferenças socioculturais presentes nessa totalidade. Portanto, o educador tem uma importante função social no sentido de atuar para a valorização dessa pluralidade, contribuindo com uma atuação que colabore para o desenvolvimento de relacionamentos pautados no respeito, na ética e na solidariedade, resultantes de uma postura evidentemente democrática e plural.

\section{Referências}

Arroyo, M. G. (2008). A humana docência. In: Arroyo, M. G. Ofício de Mestre: imagens e autoimagens. (10a ed.), Vozes, cap. 4 (pp. 50-67).

Arroyo, M. G. (2013). Currículo, território em disputa. (5a ed.), Vozes.

Arroyo, M. G. (2014a) Imagens perdidas? Imagens quebradas? In: Arroyo, M. G. Imagens quebradas: trajetórias e tempos de alunos e mestres. (8a ed.), Vozes, cap. 1 (pp. 33-52).

Arroyo, M. G. (2014b) Outro olhar sobre os educandos In: Arroyo, M. G. Imagens quebradas: trajetórias e tempos de alunos e mestres. (8a ed.), Vozes, cap. 2 (pp. 53-67).

Candau, V. M. F. (2012). Diferenças culturais, interculturalidade e educação em direitos humanos. Educação \& Sociedade, 33 (118) 235 -250.

Candau, V. M. F. (2014). Concepção de educação intercultural.: Editora PUC-Rio.

Candau. V. M. F. (2008). Multiculturalismo e educação: desafios para a prática Pedagógica. In: Moreira, A. F. M.; Candau, V. M. (orgs.). Multiculturalismo: diferenças culturais e práticas pedagógicas. (2a ed.), Vozes, cap. 1 (pp. 13-37).

Candau. V. M. F. (2016). Cotidiano escolar e práticas interculturais. Cadernos de Pesquisa, 46 (161) 802-820, jul./set.

Canen, A. (2001). Universos Culturais e Representações Docentes: subsídios para a formação de professores para a diversidade cultural. Educação \& Sociedade, 77.

Fleuri, R. M. (2018a) Construção de uma perspectiva curricular intercultural e inclusiva. In: Fleuri, R. M. Educação intercultural e formação de professores. João Pessoa: Editora do CCTA, cap. 5 (pp. 135-173).

Fleuri, R. M. (2018b). Complexidade e interculturalidade: desafios emergentes para a formação de educadores em processos inclusivos. In: Fleuri, R. M. Educação intercultural e formação de professores. João Pessoa: Editora do CCTA, cap. 4 (pp. 105-134).

Gomes, N. L. (2007). Diversidade e currículo. Indagações sobre currículo. Brasília: Ministério da Educação, Secretaria de Educação Básica.

Lima, E. de S. (2006). Currículo e desenvolvimento humano. Indagações sobre currículo. Brasília: Departamento de Políticas de Educação Infantil e Ensino Fundamental, nov. (pp. 11-47).

Marconi, M. de A. Lakatos, E. M. (2003). Fundamentos da metodologia científica. (5a ed.), Atlas.

Moreira, A. F. B. \& Candau, V. M. (2003). Educação escolar e culturas: construindo caminhos. Revista Brasileira de Educação.

Moreira, A. F. B. (2012). Os princípios norteadores de políticas e decisões curriculares. Revista Brasileira de Política e Administração da Educação, 28, 180194.

Oliveira, R.M. de, Pontes, P. A. I \& Seruffo, M.C. da R. (2022). Interculturalidade nas licenciaturas: ressignificando práticas docentes e saberes do campo. Research, Society and Development, 11 (2). https://doi.org/10.33448/rsd-v11i2.25559. 
Research, Society and Development, v. 11, n. 3, e22211326394, 2022

(CC BY 4.0) | ISSN 2525-3409 | DOI: http://dx.doi.org/10.33448/rsd-v11i3.26394

Pereira, C. L. \& Pereira, M. R. S. (2020). A emergência político-pedagógica da educação intercultural crítica na formação inicial de professores em ciências da natureza no Brasil. Research, Society and Development, 9 (7). https://doi.org/10.33448/rsd-v9i7.3941.

Pimenta, S. G. (2012). Formação de professores: identidade e saberes da docência. In: Pimenta, S. G. (org.). Saberes pedagógicos e atividade docente. 8a ed. São Paulo: Cortez (pp. 15-34).

Santos, R. B. R. dos. \& Queiroz, P. P. de. (2018). Interculturalidade: instrumento de mudança da práxis escolar. Revista Aleph: Universidade Federal Fluminense.

Teixeira, E. (2005). As três metodologias: acadêmica, da ciência e da pesquisa. (8a ed.), Vozes.

Walsh, C. (2009). Interculturalidade crítica e pedagogia decolonial: in-surgir, re-existir e reviver. In: Candau, V. M. (Org.). Educação intercultural na América Latina: entre concepções, tensões e propostas. 7 letras (p. 12-42). 